Quito 10, 11 y 12 de mayo de 2006

\title{
Coloquio Internacional Historia de la Educación Regional. Perspectiva actual en América Andina
}

Quito 10,11 y 12 de mayo de 2006

\section{Guadalupe Soasti T.}

\section{(2) OpenEdition}

Journals

Edición electrónica

URL: http://journals.openedition.org/bifea/4676

DOI: 10.4000/bifea.4676

ISSN: 2076-5827

\section{Editor}

Institut Français d'Études Andines

\section{Edición impresa}

Fecha de publicación: 1 mayo 2006

Paginación: 229-230

ISSN: 0303-7495

\section{Referencia electrónica}

Guadalupe Soasti T., « Coloquio Internacional Historia de la Educación Regional. Perspectiva actual en América Andina », Bulletin de l'Institut français d'études andines [En línea], 35 (2) | 2006, Publicado el 08 mayo 2006, consultado el 05 diciembre 2020. URL : http://journals.openedition.org/bifea/4676 ; DOI https://doi.org/10.4000/bifea.4676

Les contenus du Bulletin de l'Institut français d'études andines sont mis à disposition selon les termes de la licence Creative Commons Attribution - Pas d'Utilisation Commerciale - Pas de Modification 4.0 International. 


\title{
Eventos
}

\author{
COLOQUIO INTERNACIONAL HISTORIA DE LA EDUCACIÓN REGIONAL. PERSPECTIVA \\ ACTUAL EN AMÉRICA ANDINA
}

Quito 10, 11 y 12 de mayo de 2006

El desarrollo de la Historia de la Educación, como espacio de reflexión, en América Latina durante las dos últimas décadas del siglo pasado, ha sido consecuencia de la conformación de grupos de trabajo e investigación que han perseguido objetivos y propósitos comunes para dar respuestas y explicar las situaciones particulares de cada uno de sus países. Los problemas relacionados con la escuela y la formación de ciudadanos, la educación e integración o la interculturalidad, el género, los métodos de la historia de la educación, la historia del currículo e historia intracurricular, el análisis histórico de las políticas educativas, la historia de las prácticas educativas, la historia de la formación del educador, la enseñanza de la historia, la enseñanza de la higiene y las didácticas del pasado; así como la historia de la lectura, libros, manuales y textos escolares son los temas más recurrentes en el ámbito del estudio de la educación desde la perspectiva histórica.

En los países del Área Andina el campo de la Historia de la Educación se está construyendo desde los esfuerzos individuales; por tanto, se vio conveniente iniciar una serie de acciones orientadas a conocer estos trabajos y conjuntarlos en un esfuerzo de carácter regional, que apoye el desarrollo de la disciplina y el conocimiento de esta área. Esta primera iniciativa pretende trabajar por la construcción de una Historia de la Educación de la América Andina, es un esfuerzo por aunar voluntades individuales en un proyecto conjunto.

Este evento contó con el auspicio del Instituto Francés de Estudios Andinos- IFEA, Universidad Andina Simón Bolívar. Sede Ecuador y la participación del Taller de Estudios Históricos - TEHIS y la Universidad Politécnica Salesiana.

Durante los tres días de trabajo y reflexión se persiguieron los siguientes objetivos generales:

- Coadyuvar al fortalecimiento de la investigación de la Historia de la Educación en el Área Andina.

- Ampliar y consolidar redes de intercambio y cooperación académica de carácter individual o institucional para favorecer el estudio de la historia educativa regional.

Entre los objetivos específicos se establecieron los siguientes:

- Reflexionar sobre las posibilidades de establecer ámbitos de investigación comunes en el campo de la historia de la educación 
- Contribución al conocimiento más cercano de las realidades que en el campo de la educación viven nuestros países.

- Impulsar mecanismos de comunicación académica entre grupos especializados e interdisciplinarios que propicien el análisis histórico comparativo.

- Publicación de los resultados del seminario para compartirlo con un público más amplio, los profesores de Historia.

Durante los tres días del coloquio se debatieron sobre temas como políticas educacitvas y curriculo; educación y ciudadanía; interculturalidad y educación; manuales y textos escolares; así como genero y educación.

\section{Conclusiones}

La primera conclusión importante es anotar que los objetivos propuestos, tanto generales como específicos, fueron alcanzados.

Resultado de ello podemos anotar que:

a) Se logró constituir una red inicial de investigadores de la Historia de la Educación Regional con el compromiso de incentivar en cada uno de nuestros países la construcción de grupos interesados en la reflexión de los temas relacionados con historia y educación.

b) Para llevar adelante este propósito quedaron fijadas algunas estrategias:

- Realizar un levantamiento de información sobre historiadores que trabajen temas relativos a historia y eduación, así como de instituciones académicas vinculadas a esta tarea.

- Diseñar y elaborar sendos encuentros nacionales de investigadores, con el objeto de conocer los campos de investigación y realizar un estado de la cuestión, en cada país.

- Elaborar una base de datos conjunta de investigadores de los tres países.

- Mantener reuniones periódicas internacionales de debate y conocimiento de los temas de investigación.

c) Como objetivo de mediano plazo trabajar conjuntamente para inscribir un Simposio de Historia de la Educación Regional, en el marco del VIII Congreso Iberoamericano de Historia de la Educación Latinoamericana, que se realizará en Buenos Aires - Argentina en 2007.

d) Respaldar la publicación de las memorias o un libro que recoja los trabajos presentados en este primer Coloquio de Historia de la Educación Regional. 